\title{
When the Old Becomes the New: How COVID-19 Changed Potentially Creative Action on Facebook
}

\author{
Asdrúbal Borges Formiga Sobrinho ${ }^{1}$ \\ University of Brasília, Brazil \\ E-mail address: asdru_bal@uol.com.br
}

ARTICLE INFO

\section{Keywords:}

Creativity

Facebook

Action

Changes

Re-posting

\section{A B S TR A C T}

Psychology usually treats the creative act as both novel and adapted, a definition that can embrace the social and the cultural features of creativity. Allied to the need for social bonding and the promise of self-realization, available technological resources have enabled valuable social networks. However, social isolation caused by the COVID-19 crisis has reduced outdoor and collective personal experiences usually shared on Facebook, encouraging some users to re-publish past events. Considering that posting is potentially a creative act, hence both new and adapted, may this action now equally become old and adapted? To illustrate the question, a set of 293 posts made by twelve Brazilians with mean age of 49.7 years (SD 7.34) were collected from May 25th to June 8th, 51 of them being re-posts. The authors were interviewed about their use of Facebook, relation to others, and first re-posts published in the period. Thematic dialogical analysis was applied to the content of the interviews and led to finding new meanings about old posts. Despite a small sample $(n=12)$ and the fact that $56.1 \%$ of Facebook users in Brazil are under 35 years old, the analysis of the phenomenon can shed new light on problematization of the notion of creativity by reflecting on its role in regulation of human emotions during the COVID-19 crisis, through the action of posting legacy experience on Facebook.

ISSN: 2354-0036

DOI: 10.2478/ctra-2020-0018

${ }^{1}$ Department of Educational and Developmental Psychology, and Post-Graduation Program in Developmental and Educational Psychology of University of Brasília - UnB, Brasília - DF, Brazil.

Conflict of Interest The author declares that the research was conducted in the absence of any commercial or financial relationships that could be construed as a potential conflict of interest.

Author Contributions The author is responsible for all the procedures involving developing the main theme, consulting the literature, making the research and analysing it.

Funding This research was financed by the Coordenação de Aperfeiçoamento de Pessoal de Ensino Superior (CAPES PrInt) (Finance Code 001) and by the COPEI/Unlversidade de Brasilia, Brazil.

Acknowledgments My special thanks to all the participants of the research, who freely gave interviews. 


\section{INTRODUCTION}

In the final few months of 2019, Coronavirus rapidly spread a new infectious disease, mostly through social contact (World Health Organization, 2020). This worldwide pandemic quickly turned a virus into a deep social and cultural concern. Culture itself can be understood as a cluster of material and symbolic products of progressive human action throughout history (Valsiner, 2014). However, nowadays many human actions are constrained by the effect of a virus, which has attacked individuals and societies in an unprecedented way, causing sickness, death, or at the very least uncertainty and fear of unpredictable infection. This sequence of events has turned social contact to risk, making it hard to imagine what will follow. Even the economic impact of social isolation, which, in Brazil, began in March and eased in July 2020, has put the COVID-19 crisis among research priorities all over the world. In the face of the still uncontrolled spread of the infection, answers may come, not just from scientists directly related to medical or biological fields, but from those of varying backgrounds.

In parallel to the immediate focus on physical health, questions arise about the impact on mental well-being, and stress, a condition unequally distributed due its association with age, gender, marital status, co-existence of children and even social, political and cultural states such as collectivism or individualism (Kowal et al, 2020). Hence, greater complexity of the pandemic's impact results from uniqueness of each life and experience before and during the pandemic. Moreover, anxiety and distress (Sritharan \& Sritharan, 2020) threaten long-term consequences due to social requirements (Google, 2020) of social distancing and self-isolation (Douglas et al, 2009). Such measures vary across workplaces, schools, and elsewhere, curtailing day-to-day activity. For cultural psychologists (Glăveanu, 2020), this context can raise questions about the way that, on this scale, people handle change.

This inquiry stems from the author's own experience in trying to cope with confinement, and, after carefully scrutinizing Facebook, a suspicion that many posters have been re-cycling older posts more frequently. I might put this down to reduced mobility now that outdoor social experiences such as that offered by cultural and religious events, clubs, restaurants, and so on are restricted. Equally, by producing narratives and negotiating meanings (Jiménez Alonso \& Brescó, under review), subjects may continue to recreate the emotional connection with what or with whom it had been lost. So how can posting images of the past on a social network so geared towards the present become a creative act, oriented towards the future? 


\section{Theoretical framework}

Culture, and similarly creativity, can be understood as both a process and a product of human activity. By inviting fellow researchers to contribute to creative inquiry in this area, Glăveanu et al. (2019) emphasize a collective effort toward social and cultural procedures. Previous investigations, such as that of Celik and Lubart (2016), questions the status of creativity, once its meaning changes in different places or historical periods. Let us remember that a creator or a product will certainly earn benefits, but also pay a high price for acquiring, keeping, or missing achievements facing different sorts of constraints (Stokes, 2007), particularly when they have to confront other individual(s), an organization (Formiga Sobrinho, 2019; Formiga Sobrinho, \& Glăveanu, 2017), or a society with new ideas that can be valued as creative, or not.

Although created by an individual according to their cognitive, emotional, and conative uniqueness, an outcome will be valued as creative in keeping with environmental factors, where the individual interacts with others and even an entire society. This assumption accompanies the important consideration of the individual(s') interaction, for example, with politics, education, religion, and traditions from a given society. Thus, in its way towards the new, novel or original, creativity is a psychologically, socially, and culturally action-based phenomenon.

A creative act may be understood as an approximation between the actor and their audience, to create an outcome in the shape of "a new understanding or object that is significant for both self and other" (Glăveanu, 2015, p. 5). This leads me to consider that creative acts are somehow constrained by the individual or others, with designs, blocks, or objects, within given affordances, and cultural norms that can both preserve and renew values. Some effects of the COVID-19 pandemic even called into question cultural practices and limited individual and societal physical mobility, and even how societies must find openings for their creativity (Stokes, 2007). Creative solutions, nonetheless, may be found in new mobilities (Sheller \& Urry, 2004), connections or ways of communicating through computers or smartphones.

The pandemic applied a sharp brake on general development; it leads subjects to reflect, re-signify, and revise responses to constraints, internalized and other, both in order to cope with and even avoid the threat of physical and mental disorders, and genuine emotional setbacks. A long period of isolation can change ways of developing activities together (Martino, 2001), at different levels of interaction according to meaning-making processes (Formiga Sobrinho \& Glăveanu, 2018). In short, it causes an alteration in interpersonal communication styles. Such (inter)action usually occurs physically, and although complemented by devices and platforms, it steers the way people use a social network 
like Facebook to 'meet' others. This brings me to question the concept of creativity as a knowledge-based capacity to produce something simultaneously new yet adapted (Lubart, 2007) at a time when people are still trying to make sense of what is really happening and in the place of contemporaneous ones, have begun to post legacy images.

Assuming that as pandemic victims, most subjects experienced the non-linear stages of making sense of the situation; reflecting and working towards what Glăveanu (2020) and Beghetto (2020) term the possible, creativity here is framed within the act of (re)posting itself, and not just from the content of the posts, which alone may not be creative at all, simply representing people's everyday lives such as celebrations at work, social encounters with family or friends and trips or distraction. Borges and Linhares (2008) describe a research subject who values the act of photographing over the photograph itself, a case similarly detailed in Barthes (1984). Correspondingly, my focus is more on re-posting than on the strict content of the posts themselves. During this isolation period, re-posting can be a reaction to many constraints, in a struggle against current setbacks or threats of emotional upsets, forcing people into internal problem-solving modes whether they want to or not.

A second potentially creative act, which will be complementarily analyzed, took place during the interviews, when each of the twelve participants was able to assign new meaning to their legacy posts. These posts mediated the final part of the conversation and contributed to the production of narratives, facilitating access to each one's unique openness to experience. More than a trait to indicate, for example, an adolescent's chance to express creativity on social networks, openness to experience, can influence management of vulnerabilities and, at least internally, to confront cyber bullying (PérezFuentes et al., 2019). According to the authors, expressing creativity individually may not be enough to deal with expressions of others and - perhaps even more importantly, the reactions of others in any audience. This highlights the role of peers and others in acting creatively on networks, since individuals can be positively influenced and strengthen their own self-esteem in their teens.

Focusing on the playfulness of the language used on Facebook, Lewin-Jones (2015) explored ways in which humor can connect people aged between eleven and sixty years. However, the creative stimulus in this instance is product-based, emphasizing the linguistic tokens of one's cognitive abilities to create. This makes the approach presented by the author quite different from the cultural and action-based approach adopted here. Particularly in adulthood, as shown in Savas (2017), the action of posting by members of two Facebook groups in Turkey is viewed as creative, as it mostly shares narratives and 
life stories in the shape of personal photos and testimonies. However, it is not the medium or the content itself that can make the action creative, but the affective impact on other participants who can - and usually do - comment and progress the communication. This takes place, for example, by similarly sharing their memories and reinforcing materialization of a dynamic, fluid, and evolving collective memory based both on a sense of belonging and on a struggle with a sense of loss.

Hargreaves and Hartley (2016) treat the concept of creative citizenship by considering how social networkers create their unique associations according to the affordances of the virtual environment and to their experiences 'inside' it, with people they barely know. Girginova (2017) exemplifies creative citizenship by closely analyzing the campaign \#savethesurprise. In an effort to keep secret the details of the 2012 London Olympics opening ceremony, organizers asked witnesses of the rehearsals not to share previews on social networks. The main event was TV broadcast to the world in real time, and 100,000 people did not give the game away. Thus, the strategy for engagement in a good cause was successful and proved how subjects could be motivated by soliciting a shared sense of national belonging.

Mainsah (2017) mentions the different facets of the "active construction of citizenship through social media" (p. 1) by considering challenges, potentials, and meanings involved in everyday creative acts on social media, such as storytelling, sharing photos and experiences from different domains. However, the author emphasizes engagement of individuals and groups who understand the activities as transformative, as a condition in framing their activity as creative citizenship. Despite the importance of the concept and the diversity of possible applications, this paper chooses not to work with the abstraction of creative citizenship. It certainly can act as a backdrop to the re-posting phenomenon, as long as each research participant also acts collectively and shares some purpose on Facebook. They do not yet form a group apart from their interconnection being reinforced by algorithms or other technological affordances (Reviglio \& Agosti, 2020). In other words, in spite of doing this by chance, they have not organized themselves around any cause whilst communicating with each other and with the world (Bennett \& Segerberg, 2012).

Most of the social connections within my research sample were established 'outside' the social networks, but have a role in strengthening individuals' creativity to act against threats from the present time and from the 'real' world. Thus, re-posting is a phylogenetic and ontogenetic action (Vygotski, 2001), since it occurred at a moment common to all, and when the larger action already had a history. However, on this occasion, re-visiting the content afforded character to the action, which began with legacy content already 
viewed as nothing unusual, yet capable of becoming exceptional through the narrative (Bruner, 1997) revised with new comments made at least by the own poster.

The interaction between internal and external contexts of each author-generated meanings within a creative process affected not only by social distance, social isolation and other repercussions of the pandemic, but also by the dialectical presence of the researcher who posed questions, showed artifacts to symbolically mediate the dialogue and led the communication. Such interaction, which provided a potential source of novelty 'ended' with new meanings emerging from the polysemy and polyphony of the narratives (Bakhtin, 1992; Caixeta \& Borges, 2017). The interviews, which discuss legacy items reposted into the present yet directed towards the future, involve potentially creative thought and action through mutual uncertainties with and about others on a path to the possible (Beghetto, in press). Hence, the inquiry may be well-placed within the study of creativity and cultural psychology.

Thus, uncertainty and disquiet (Tateo, 2016) are already being felt by each poster. Risk taking, on its turn, more than just a trait of creative people (Lubart, Zenasni, \& Barbot, 2013), plays its part in the struggle against restrictive and unforeseen events. This makes creativity welcome or even mandatory to succeed in a near future, where the mental consequences of the pandemic, such as stress, anxiety and depression, might well become more embedded among many of the survivors. What follows aims to show whether or how potentially creative actions can provide a means of avoiding or reducing such repercussions.

\section{METHOD}

\section{Participants}

The inquiry was reviewed and approved by the ethics committee of the University of Brasilia - UnB, registered by protocol number 34721620.9.0000.5540, with participants providing their written consent to guarantee anonymity and freedom to quit the research at any time. This paper refers to each one as a number following the letter $P$. Twelve members $(n=12)$ of my own social network were chosen, as long as they re-posted, from May $25^{\text {th }}$ to June $8^{\text {th }}, 2020$ a period when most Brazilians were confined to their homes, although permitted essential journeys to supermarkets, drugstores, or hospitals. Through Facebook Messenger, the posters were invited to participate with no remuneration. The age range of the sample fell between 35 and 60 years with a mean age of 49.7 years and standard deviation of $7.34(S D=7.34) .50 \%$ were male and $50 \%$ female. Three subjects live alone, three cohabit with children and six, with youths and/or older people, data registered in profiles but, in the end, this did not affect the scope of this research. All are Bra- 
zilian, but eleven live in Brazil, nine in Brasília, one in Rio de Janeiro, one in Teresina, and just one, in Washington D.C., USA. Table 1 summarizes their profile.

Table 1

\section{[Poster's profile]}

\begin{tabular}{|c|c|c|c|c|c|c|c|}
\hline Name & Gender & Age & Profession & $\begin{array}{c}\text { Marital Status I } \\
\text { cohabitation }\end{array}$ & City & $\begin{array}{l}\text { Number of } \\
\text { posts from } \\
\text { May } 25^{\text {th }} \text { to } \\
\text { June 8th } \\
\end{array}$ & $\begin{array}{l}\text { Number of re- } \\
\text { posts from May } \\
25^{\text {th }} \text { to June } 8 \text { th }\end{array}$ \\
\hline P1 & Male & 43 & Designer & $\begin{array}{l}\text { Single / lives } \\
\text { with parents }\end{array}$ & $\begin{array}{l}\text { Brasília - } \\
\text { DF }\end{array}$ & 1 & $\begin{array}{c}1 \\
(100 \%)\end{array}$ \\
\hline $\mathrm{P} 2$ & Female & 53 & $\begin{array}{l}\text { University } \\
\text { Teacher / } \\
\text { Artist }\end{array}$ & $\begin{array}{l}\text { Married / lives } \\
\text { with her family }\end{array}$ & $\begin{array}{l}\text { Vitória - } \\
\text { ES }\end{array}$ & 36 & $\begin{array}{c}5 \\
(13.8 \%)\end{array}$ \\
\hline P3 & Male & 52 & $\begin{array}{l}\text { University } \\
\text { Teacher }\end{array}$ & $\begin{array}{l}\text { Single / lives } \\
\text { alone }\end{array}$ & $\begin{array}{l}\text { Brasília - } \\
\text { DF }\end{array}$ & 32 & $\begin{array}{c}1 \\
(3.1 \%)\end{array}$ \\
\hline P4 & Female & 46 & $\begin{array}{l}\text { University } \\
\text { Teacher }\end{array}$ & $\begin{array}{l}\text { Married / lives } \\
\text { with her family }\end{array}$ & $\begin{array}{l}\text { Brasília - } \\
\quad \text { DF }\end{array}$ & 2 & $\begin{array}{c}2 \\
(100 \%)\end{array}$ \\
\hline P5 & Male & 54 & $\begin{array}{l}\text { Software en- } \\
\text { gineer }\end{array}$ & $\begin{array}{l}\text { Married / lives } \\
\text { with his partner }\end{array}$ & $\begin{array}{l}\text { Wash- } \\
\text { ington - } \\
\text { DC }\end{array}$ & 60 & $\begin{array}{c}6 \\
(10 \%)\end{array}$ \\
\hline P6 & Male & 47 & $\begin{array}{l}\text { Economist / } \\
\text { Civil Servant }\end{array}$ & $\begin{array}{l}\text { Married / lives } \\
\text { with his family }\end{array}$ & $\begin{array}{l}\text { Brasília - } \\
\text { DF }\end{array}$ & 8 & $\begin{array}{c}1 \\
(12.5 \%)\end{array}$ \\
\hline P7 & Male & 51 & $\begin{array}{l}\text { Agronomist / } \\
\text { Civil Servant }\end{array}$ & $\begin{array}{l}\text { Married / lives } \\
\text { with his family }\end{array}$ & $\begin{array}{l}\text { Teresina } \\
-\mathrm{PI}\end{array}$ & 4 & $\begin{array}{c}2 \\
(50 \%)\end{array}$ \\
\hline P8 & Female & 35 & $\begin{array}{l}\text { Lawyer / Civil } \\
\text { Servant }\end{array}$ & $\begin{array}{l}\text { Single / lives } \\
\text { alone }\end{array}$ & $\begin{array}{l}\text { Brasília - } \\
\text { DF }\end{array}$ & 4 & $\begin{array}{c}4 \\
(100 \%)\end{array}$ \\
\hline P9 & Female & 60 & $\begin{array}{l}\text { University } \\
\text { Teacher }\end{array}$ & $\begin{array}{l}\text { Widow / lives } \\
\text { with her family }\end{array}$ & $\begin{array}{l}\text { Brasília - } \\
\text { DF }\end{array}$ & 49 & $\begin{array}{c}5 \\
(10.2 \%)\end{array}$ \\
\hline $\mathrm{P} 10$ & Male & 42 & $\begin{array}{l}\text { Artist / Uni- } \\
\text { versity } \\
\text { Teacher }\end{array}$ & $\begin{array}{l}\text { Single / lives } \\
\text { alone }\end{array}$ & $\begin{array}{l}\text { Brasília - } \\
\text { DF }\end{array}$ & 3 & $\begin{array}{c}1 \\
(33.3 \%)\end{array}$ \\
\hline P11 & Female & 58 & Journalist & $\begin{array}{l}\text { Divorced / lives } \\
\text { with her family }\end{array}$ & $\begin{array}{l}\text { Rio de } \\
\text { Janeiro - } \\
\text { RJ }\end{array}$ & 28 & $\begin{array}{c}19 \\
(67.8 \%)\end{array}$ \\
\hline $\mathrm{P} 12$ & Female & 56 & $\begin{array}{l}\text { Movie Mak- } \\
\text { er / Universi- } \\
\text { ty Teacher }\end{array}$ & $\begin{array}{l}\text { Divorced / lives } \\
\text { alone }\end{array}$ & $\begin{array}{l}\text { Brasília - } \\
\text { DF }\end{array}$ & 66 & $\begin{array}{c}4 \\
(6.06 \%)\end{array}$ \\
\hline \multicolumn{6}{|c|}{ Total number of posts / re-posts } & 293 & 51 \\
\hline
\end{tabular}




\section{Material}

The dataset included 293 posts, with an average of 24.41 (SD = 24.15) posts per participant during the period; and 51 re-posts, with an average of $4.25(\mathrm{SD}=4.99)$ re-posts per participant. The re-posts represent $17.4 \%$ of the total posts made by the participants. The average percentage of re-posts among the totality of regular posts was $42.23 \%$ (SD = 39.77). The captioned images - the first one being a spontaneously found re-post from each author - were captured and kept on my PC for reference during interviews carried out through the video-conference platform Jitsi (meet.jitsi.si) or by WhatsApp audio call, totaling 2 hours and 17 minutes, with an-unset mean time of 21.4 minutes. Each participant was previously contacted by Facebook Messenger to schedule the interview, while content was transcribed for further consultation and analysis.

\section{Procedure}

I chose the method of mediated interview, a kind of semi-structured procedure, in which the interaction between subject and interviewer is mediated by an artifact (Caixeta \& Borges, 2017), which can symbolize the participant's relation to the world (Vygotsky, 2001) and thus aid meaning processes during the narration. The interview began by explaining the nature of the research and asking: (1) for a description of each user's relationship with Facebook; (2) whether something new had been noted on their timeline during the lockdown period; (3) whether something recurrent or unique had been seen; (4) whether the subject's Facebook use had changed during the lockdown period; (5) and, finally, what could they say about the collected post shared with each author at that particular moment of the interview.

Only in the final part of the interview was the emerging aim of the research detailed in order to avoid any bias related to direct questions about creativity. According to the way creativity is framed here, not only as product but also action-based process, the association between the last question and the post was inspired by a study by Borges and Linhares (2008), which describes a subject who places greater value on the act of photographing than on the photograph itself, a case similarly detailed in Barthes (1984). Taking the theme as a notion emerging from similar statement structures (Bakhtin, 2006) set by external elements (Lotman, 1978), the analysis procedure followed the thematic dialogical technique (Silva \& Borges, 2017, p. 251), which consists of: (1) interview transcription; (2) setting of units for analysis; (3) intensive reading of the transcribed content; (4) organization of the statements into themes and sub-themes (analysis of recurrences, correlation and similitudes of meanings in the statements); (5) development of semiotic maps which will be presented in the shape of word clouds. 
The analysis was developed according to these stages, in an attempt to understand the way the participants acted according to their statements. During this procedure, statements were compared to others made by the same and other participants, particularly where the contents revealed tensions and presented contradictions relevant to understanding each one's thoughts and actions in relation to themselves and/or to the others. This procedure resembles that adopted by Marková et al. (2007) to develop dialogical analysis in focus groups. However, in our research the implicit dialogue between participants was framed according to the following stages.

The five steps of analysis contributed to a reorganization of the five questions because the content of the answers to question 1 led to the approach of goal-oriented actions of each poster in the use of Facebook. The application of the thematic dialogical analysis technique can be instanced by the unit of analysis, named "keep contact with friends" (P1), perceiving this goal-oriented act as a way of expressing affection or a way of counterbalancing the lack of physical demonstrations of affection. Moreover, most participants reveal polarization in political matters and suggest some intolerance through interaction with their strict pairs or people with similar opinions. Thus, affection is characterized on one side and intolerance on the other, interestingly feeding off each other as both actions and reactions on Facebook. Similarly, while considering the importance of politics for all those interviewed, P9 mentioned the increase in social criticism, personal confession and premonition in the content of posts, at one point in the interview, and as a new trend that most people have adopted elsewhere.

Responses to questions 2 and 3 refer to the identification of novelty produced by others on the social network. For example, P5 mentioned that space is available for individual posts, but no one wants to read, see, or hear, just to be read, seen, or heard. Facebook itself can be contradictory by permitting more dialogue, but not really promoting it. As a result, one can easily block disagreement or opposing opinion. Moreover, algorithms 'applied' by the social network (Reviglio \& Agosti, 2020) aim to connect people with views and pursuits they have in common. Thus, the potential to become a new environment, where different people can 'join together' and exchange ideas, is threatened by polarization, under the risk of perpetuating existing values.

Answers to questions 4 and 5 refer to identification of novelty produced by the individual in a quarantined environment. For example, P9 mentions that she has read many polarized posts referring to politics and reads this as a sign of social division within the network. On the other hand, the same subject, who appears critical towards others' behavior, activated a filter to restrict displeasing access to her posts. Thus, she adopts the 
same behavior pattern she criticizes, which can be detrimental to creativity in other domains. However, in terms of creativity and the visible communicative outcome represented, P9 is characterized by a unique relation with her post, her sense of loss and with Facebook, which will be detailed later. The following section develops the model of analysis in subsections organized according to the sequence of the preceding three paragraphs.

\section{RESULTS}

To advance the discussion of what on Facebook, in the context of this inquiry, is new or old, this section reports how each and all subjects act, interact and react therein. The section is divided in three clusters referring to main themes which aroused from the interviews. Each of them is detailed in the following sequence.

\section{Goal-Oriented Actions in the Use of Facebook}

In 2015, Facebook launched On This Day, a page dedicated to reminding users of oneyear anniversary of a content they had shared. Initially, only the user can see the content, but can then also decide to pass it on (Gheller, 2015). This might be an appropriate device for a lockdown, helping people recall and share happy moments possibly related to trips and having fun with friends (P7 and P8), successful work projects (P6 and P12), and good times for all in general. Many Facebook users replaying those posts during the pandemic may thus be trying to disseminate "positive achievement themes" (Pillemer et al, 2013 , p. 214). Other items are related to success or accomplishments at work (P2, P3, $\mathrm{P} 4$, and P10) and "positive interpersonal themes" (idem) related to family, friendship, and love shared (P1, P5, P9 and P11) in the shape of celebrations during a period when people were feeling keenly affected, if not threatened emotionally.

Moreover, feelings of loss were directly and indirectly mentioned by all interviewees, during the interview, eliciting a contradiction with the positive interpersonal themes. The loss of a partner motivated P1 to return to Facebook with the idea of sending messages to his family and mutual friends, which could be accessed on the network, to where he returned during the pandemic. Referring to different levels of privation, he noted that "Everybody had plans shattered by this pandemic, especially in Brazil, due to poor political management." He was referring to a political situation, which was already worsening as the population came to feel itself almost abandoned to its own fate whilst many of the collective setbacks of the pandemic increased.

P8, at thirty-five the youngest participant, mentioned that she returned to Facebook to keep in touch with her friends when about five years ago, she had re-located to another city. She said, "today it is something I like because it helps me remember." This statement became interesting, as one would expect her to be the subject with fewest accumu- 
lated memories. However, missing friends and companions who live elsewhere, the fun they shared, and from whom she became separated, encouraged her to return to the network and to re-post past events, which, while not yet transposed into an imagined future, can at least fill the increase in her free time.

Figure 1 below summarizes the main themes of this stage of the interview (i.e., keeping contact with distant friends and family or those isolated by the pandemic are recurrent in the participants' statements). The same can be concluded about exchanging information, particularly news (P3 and P5), and professional issues (P1, P2, P6, P10 and $P 12)$. The final theme is based less on shared content than on the contact afforded by the network even to remembering those present, or to be remembered by others. P11, P9 and P8, more than the other interviewees, emphasized the role of Facebook as a repository, a place to keep photos, for example. The entire group of examples refers to Facebook both as a 'place' visited to get up to date on the news and the fait divers people share, and to noting new and re-visiting old posts made by past acquaintances, even sharing sentiments through poetry.

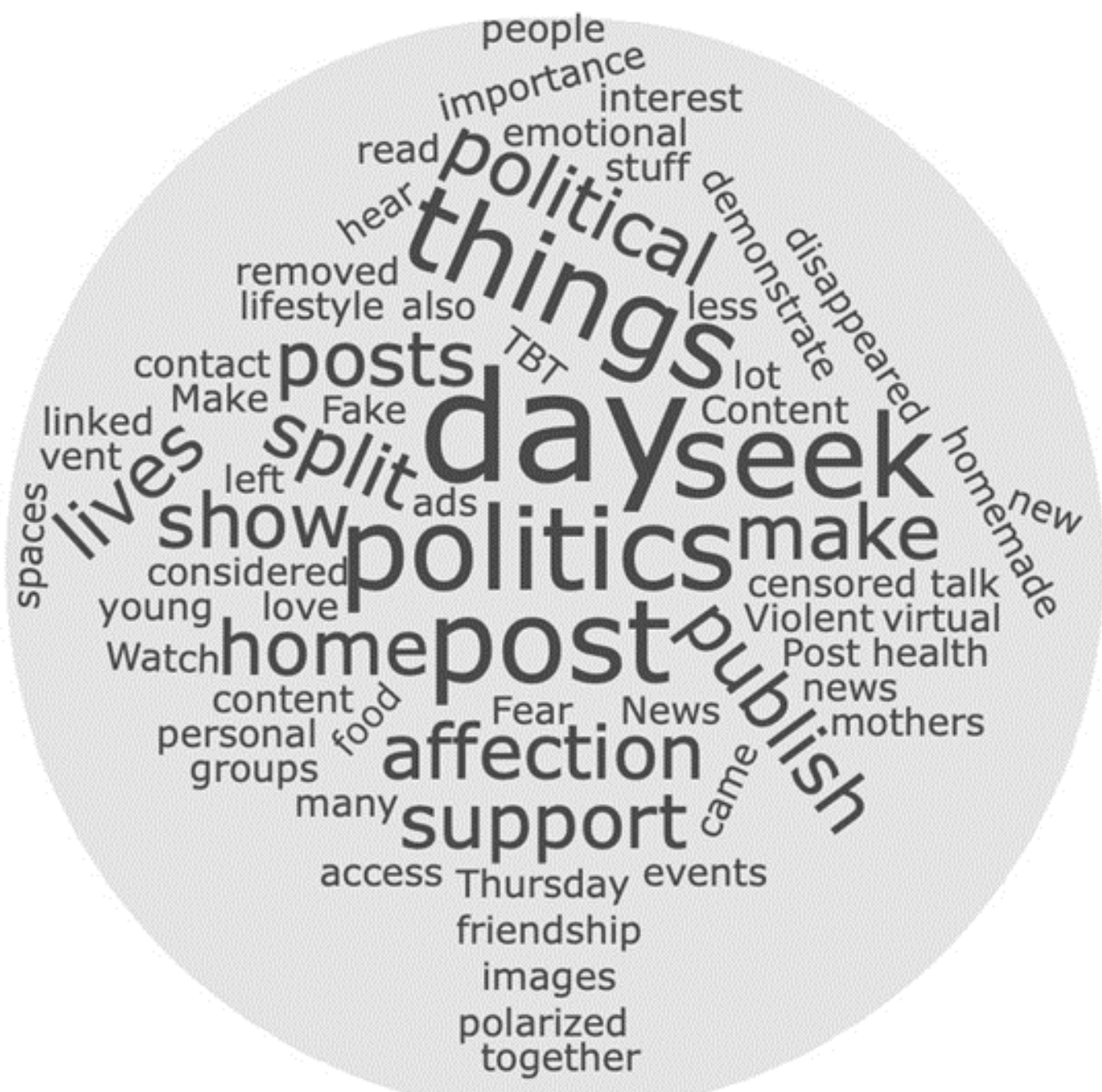

Figure 1. Goal-Oriented Actions 


\section{What is Going on With the Others?}

P1 referred to the wider action of re-posting by saying that "people had the notion of being time affected. Time for the privileged, and isolated among us got messed up. Underlying but unseen control by time is exposed." This statement summarizes the condition of all interviewees during lockdown, raising time as an essential factor for understanding the phenomenon within the approach of cultural psychology, and also as a representation of an upset in the organization of routines. However, P1 mentioned that he has made the most of his free time observing a large number of live videos, while P6 thought it positive for many people to make and view such items. This activity requires planning and organization of the routine, particularly when there is an interest in a specific domain. By making themselves available to watch such transmissions, or "lives," the participants can increase knowledge and their capacity to innovate. In summary, even re-organized time can contribute to creativity drawing upon goal-oriented actions connecting past with future and so they may be characterized as retrospective and prospective (Boym, 2007). Therefore, both time and creativity also are related to some Facebook characteristics.

It is important to note the mean age of the interviewees (49.7 years). P3 mentions a "drastic decrease in young people accessing. Maybe due to other social networks, like Instagram, whose more visual language style attracted many of the young. Users seem to be ageing. To the young, such networks often are not an interesting space for interaction." This participant may well be right; $56.1 \%$ of Facebook users in Brazil are under thirty-five, while $39.8 \%$ are between thirty-five and sixty-four (Navarro, 2020). Even so, it is important to consider that the condition of people living along with younger members of family environments beyond the network would be enough to affect the significance of time. It is also important to question whether spending more time in the virtual world is a younger person's preference. In the U.S., a survey noted a decrease in the use of social media as age increases (Hruska \& Maresova, 2020), but I might question if the assumptions apply during confinement, when younger people and the middle-aged, for example, can make equal use of social networking.

Following with the approach of collective impact of the pandemic found in the contributions of the participants, P10 remarked that "we are living through collective distress. I think this is what connects us: the suffering, the frustrations, all those feelings of loss, restraint, added to the need for financial and mental organization." This statement emphasizes suffering and, at the same time, suggests that individuals are stronger together when coping with distress. P5, in turn, believed it is its potential to reinforce social bonding that is the great value of Facebook and remarked: "The pandemic united many people. Some individuals will leave it more solid." Thus, he alluded to the strengths emerging 
from oneself in relation to others' suffering during this period, and also once during his interview his own personal hope. He is totally aware of the damage caused by the 'politicization' of the health crisis both in Brazil and in the U.S. Interestingly, politics became a central issue in the texts on suffering. Even the participants who shared positive achievements somehow mixed their social bonds with accomplishments at work, where they are likely members of teams. This makes the achievement and interpersonal 'categories' co-dependent and also shows awareness of the political threats to an individual and to the collective. The activity in question can become an important step towards a future appreciation of creative citizenship (Hargreaves \& Hartley, 2016).

P3 highlights another common lockdown phenomenon: the number of posts in which people reveal their ordinary lives is very reduced. Themes refer mostly to the pandemic, deaths, bad management of the public health system and Brazilian politicians. Facebook is no longer the right place to know about people's day-to-day time. It feels stolen.

This statement revealed the influence of the pandemic over people's lives, tellingly reflected by the content they post on their networks. However, other participants referred to this stolen day-to-day time by considering the relevance of the themes most people have been posting about, such as the increased number of food images (P7), hair dressing (P1), and others, revealing boredom (P8) or fear of sharing lifestyle issues (P10). To these already varied meaning of changes in sharing - or not sharing - day-to-day time, some alteration of meaning can be added, such as comfort (P12), support (P5, P2, $P 9$, and P12), and affection (P11). All may be sought or offered, even through making ordinary posts and carrying meanings determined with other people, and thus through individual and collective actions. It could be assumed that, once daily life is constrained, so may creativity be, which has it as its main source. However, this may not be the case when re-posting positive legacy events, contributing to or at least imagining, if not really creating, future events, as a kind of mechanism for emotional self-regulation.

P12 noted that "people are easier about coping with all of this [issues of the pandemic]." It is important to stress that, as P6 and P7 mentioned, political posts have been progressively replaced by other issues, perhaps because people are tired of so much complaining. Either way, whether they want it or not, during the pandemic subjects were gaining time to cope with negative feelings of loss and grief felt by themselves or by others. Moreover, with the 'politicization' of health and the impact of the pandemic, people did not always manage an escape from thinking or talking about politics, opting instead for support or affection, as figure 2 demonstrates. 


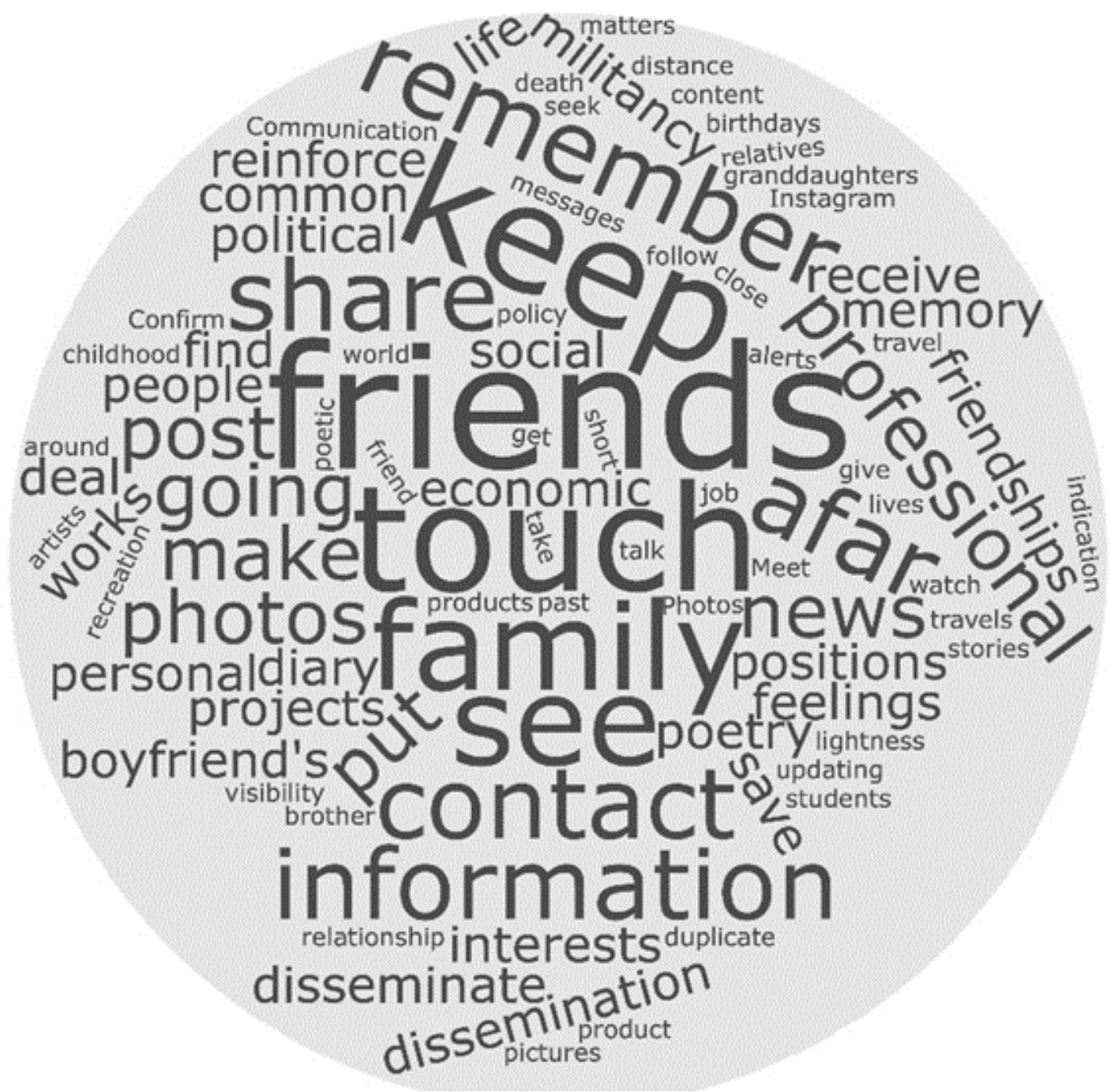

Figure 2. What is Going on With the Others?

\section{What's New With Them?}

P8 summarized the re-posting phenomenon by saying that "most people are turning Thursdays into TBT [throwback Thursday]," but had not considered anything beyond trying to improve her mood by re-posting. According to the way we see creativity, this can mean a potentially creative action and although it was not mentioned when it comes to talking about goals, it was similar to what other participants do. In other words, turning any day into a TBT, unlimited by abbreviation or acronym, is not enough to prompt creativity, unless a collective act becomes also relevant from the standpoint of the participant. Whether referring to moments of happiness or suffering, the re-posts express nostalgia, often disguised or tinged by affection. In their responses, P2, P3, and P7 all depicted their re-posts as occasions to be close with friends and families, recalled good times, while at the same time being accompanied by a feeling of privation, with no prospect of recovery. However, P7 refers to posts about pets or some domestic issues left undone 
from before the lockdown. This fact alone can reveal changes in connected thinking, doing and feeling, and impact on other people with whom he is in contact, possibly opening the path to creativity. Similarly, P6 referred to the pride he felt when re-posting a joyful meeting with a team he had worked with on a project. As a civil servant in a political organization, he would have liked more opportunities to succeed with work tasks. As with many other people stressed by the pandemic, he will need to use his creativity to make that happen.

P1 noted that "people in Brazil use social networks to keep in touch with friends." However, his re-post advised those who do not accept homosexuality to exit his contacts. According to his interview, the content appeared as a way of telling his contacts he was back and was a preparation for strictly new posts in the future. P2 equally refers to friends and misses physical contact with an artist colleague. P9, whose re-post is detailed below said likewise of her family. In fact, despite the increased time on the social network, where most social life was taking place, many participants still felt comfortable among their equals in beliefs, opinions, age, and profession. Such factors, allied to friendship, warmth, and support expressed through shared messaging may have forged bonds. However, they may equally have joined people up with others of the same type, thus weakening the diversity of ideas so necessary for enhancing creativity, especially during a period when its needs were greater than ever.

For instance, P4 mentions she was missing being with her students as her re-post showed: "You can see them smiling. We miss this togetherness That is what we express: the good moments with other people have gone missing." She pointed to the specialness of teaching, which so depends on the deployment of social skills. Equally, subjects who shared positive achievements at work also referred to inspiration and collaboration in projects, and drawing on the motivational support of others.

P12 posted a picture of herself embracing a woman about whom she made a film. Both are holding brooms and are about to sweep the space where the documentary was to be shown, P12 declaring: "That woman inspired me so much." Such was the way she referred to one of her characters, while showing affection and sensibility through the picture. P5 and P3 simply re-posted pictures of people they loved and missed, keeping friendship and affection separate from their work, perhaps not realizing any connection between each image and creativity. P10, in turn, said he has not been posting about work because he has not been going to the office. However, his re-post concerned work, involved political issues, and showed students engaged in a project. Interestingly, he said: "For me, remembering offers a chance to re-signify the fact, to turn the situation produc- 
tive." The way he refers to his post clearly points to a transition from the present to the past, with the aim of future change, through his work with the visual arts. Thus, his way of understanding his own action of remembering, as well as his work, is already related to creating.

Here, the importance of social interaction at work, or for successful project outcomes, is not confined to teachers. Those educationists in the sample who shared positive work achievements also followed extra-mural professional activities, some teachingrelated, linked to university curricula. Motivation for social bonding comes from different sources (Lubart, Zenasni, \& Barbot, 2013) and is socially and culturally shaped (Hennesey, 2016). It is, when accompanied by positive moods, an essential antecedent of creativity, albeit not as exclusively as in the structured contexts emphasized by Hennessey and Amabile (2010). Ultimately, the virtual environment could not disguise the strength of social bonds for coping with the emotional impact of societal, cultural and political changes (Savas, 2017), most of them exposed and fixed by the pandemic, nor indeed for creativity, despite the subtlety of the latter. In fact, during and beyond the pandemic period, the traditional forms of social bonds might even be strengthened, especially in coping with varying types of privation.

The most intense sense of loss was expressed by P9, whose husband had died two years earlier. As a 60-year-old, and more vulnerable to falling ill, she was more strictly confined to home while dealing with returning grief. On her re-post, she said: "We were a happy couple. I do not remember any sadness. I even shared [the post] as a good memory: our history and our son and daughter." She added: "I love the photos which remain in the memory. This pandemic is recalling those times together and the month we found out he had cancer." She referred to a continuing grief and to Facebook as a source of memory to keep her photos of events and friends, particularly since transforming her husband's profile into a memorial after requesting its closure. This detail may be related to the fact that she is a woman, a widow, and a university teacher with a PhD in Psychology.

The affection and unexpected joy in mentioning bereavement also appears in the speech of P11: "Facebook [automatically] reminds me of my dad, and the good days I spent with him. Seeing these pictures brings back a joy about those times, full of affection." Both examples of P11 and P9 characterize unique experiences (Jiménez Alonso, Brescó, under review), which can be extended to loss of a different type. They also put in question the instantaneity and superficiality of the information on a social network, as they can also be used to keep or activate memories and intensify feelings. Consequently, subjects can move on in their lives. 
Questions might be raised, such as, "Is Facebook trying to 'return' to users what P3 terms their "stolen day-to-day times?" or, "Are people really re-living this lack of day-today life by re-posting it?" There must be different answers to these questions, but for the moment Figure 3 summarizes the main themes of this last section by emphasizing the centrality of people, which should not be extraordinary in the context of a social network. However, it can somehow be surprising when mostly related to photographs, loss, memories and regret, for example.

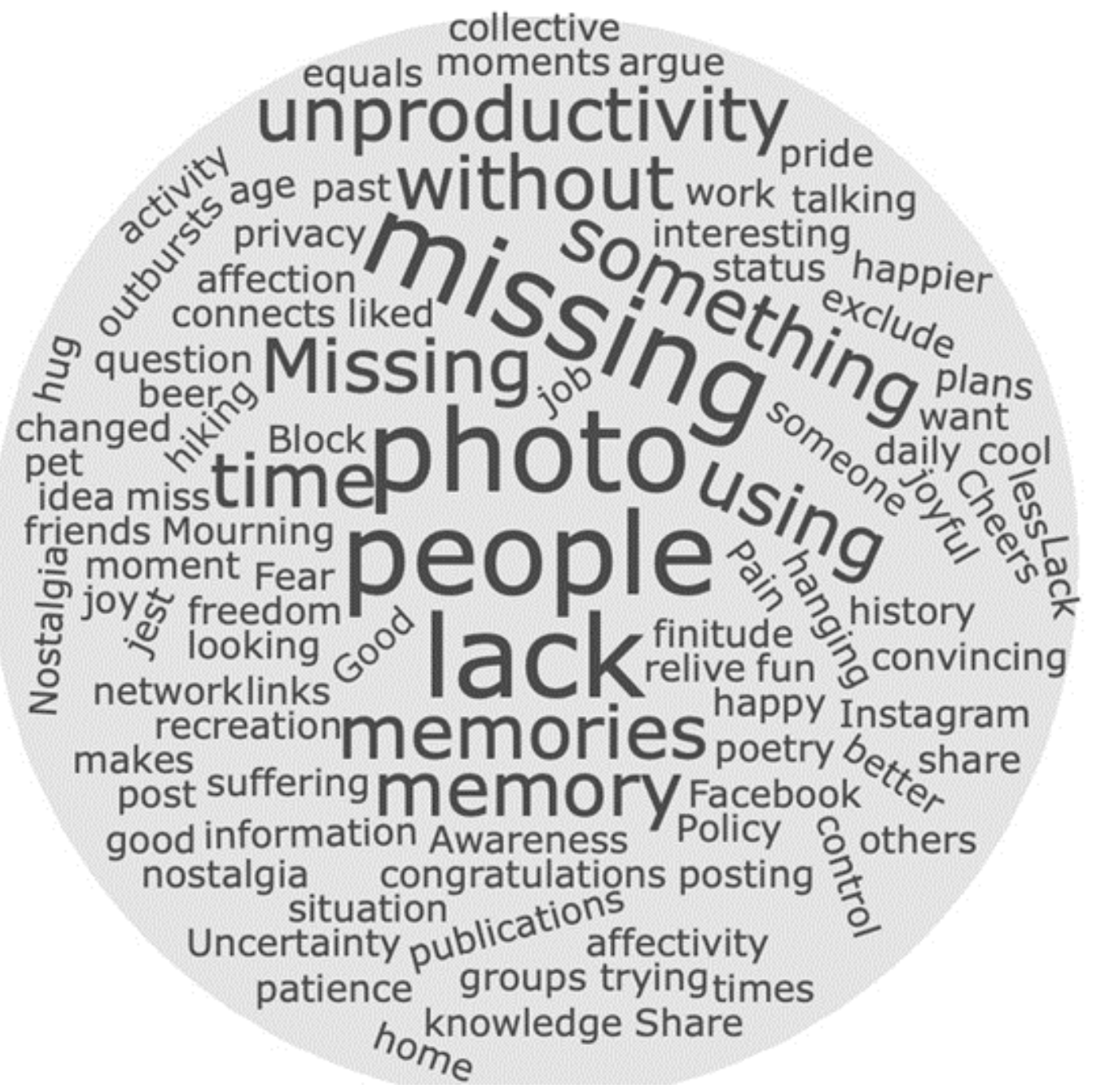

Figure 3. What's New With Them?

\section{Discussion}

This paper has been approaching the re-posting phenomenon as a way of reflecting about one important definition of creativity in Psychology. Framed in the context of lockdown caused by COVID-19 pandemic, the act of some Facebook users in Brazil can be meant potentially creative according to the way legacy posts are re-signified. Meanings related to the way the posters refer to Facebook, and to the content of posts made by themselves or by others were presented in the last section referring to goal-oriented ac- 
tions, ways of interacting with others, and ways of understanding their own experiences. In the current section the findings will be deeply discussed in order to reflect about novelties brought by old posts.

All subjects of the present study stressed the role of social bonding to counter setbacks or constraints during the pandemic, revealing internalization of the vision of others with whom they have been sharing values or have somehow been coping with the lockdown. Social bonds eased by networks such as Facebook can be essential for creativity and for protecting people from splitting and becoming more vulnerable, as a consequence of political opinions, for example. It can be very important also to protect people from general malaise, given that legacy posting can point to future mental health issues concerning the uncertainty surrounding the length of the pandemic and its subsequent outbreaks (Sritharan \& Sritharan, 2020).

It seems some have shared their past experiences in search of "a more creative way of coping with everyday or even increased uncertainties" (Tateo, 2016, p. 43), enabling creativity as a way of looking to the past, so as to adjust feelings in the present, whilst preparing for the future. One hopes the feelings expressed by the participants meet a temporary emotional need, possibly showing them how to cope with negative moods, to manage their feelings and shared experiences with others, in short, to make sure they are not alone. This emotion regulation strategy could also have helped each of them resignify many things even about themselves, making life changes and possibly opening new roads to the future.

Beyond the device of the information bubbles, which places contacts into strict pairs and can impair personal creativity by restricting pluralism of data, actions and interactions (Reviglio \& Agosti, 2020), the sharing of experience, as well as that of preserving a public memory by Facebook groups exemplified by Savas (2017), suggested a quest for emotional support mixed with the readiness to leave negativity behind and somehow overcome the distress of the pandemic, even if it was just by re-creating posts. Hence, people seemed to be travelling against time while they gathered enough strength to confront the present and move forward. The shocks wreaked by the pandemic, however, are huge with still unknown resolutions. Thus, to balance the limits on movement, each participant, through imagination, was finding their own ways to advance. In their affirmative communication with others, they joined the ever-increasing traffic on social networks to journey from bad to good emotional states. Thanks to legacy-posting they were on a kind of trip to the future whilst in the here and now (Zittoun et al, 2013). 
Equally, people can tire of re-posting or, one hopes, discover other ways to use Facebook. They can be open to affection and support, like P2, P5, P9, P11, and P12, acquiring new activities to develop at home (P6, P7 and P12), or to sharing work experiences (P1, P4, and P10) with an optimistic take, while helping others face their setbacks during the pandemic. All of these examples refer to individual attitudes and actions that emerge and occur in relation to others (Bakhtin, 2006), since many people have been engaged in re-posting during this stage of the pandemic in Brazil. Thus, the process of reposting has become reflexive, in a way that the individual can treat their own lack of affection and support by sharing out to others on their timeline. Hence, a subject's wellbeing can be improved by positive moods and make the 'individual space' more favorable to creativity even at home, which has become the workplace for all the participants and of many others around the world. There are openings for new and creative solutions from different areas to overcome the emotional toll of the Coronavirus - stress, anxiety, and depression - as in the West China Hospital, when it formed teams of health and social workers delivering intervention and rehabilitation processes (Lima et al., 2020).

Attempting a sample of individual experiences, I may assume that the collectivist aspects of culture (Celik, \& Lubart, 2016; Kowal et al, 2020) achieve greater importance. Thus, no matter how far Brazilian culture may be labelled from collectivist or toward individualistic (Lubart, 2010), the action of posting also reflects values and shared norms, possibly even subverted by the audience, since each participant had used Facebook for over five years. All cited reactions anticipated, emotions and feelings shared, and support given or received, referred also to externalization (Vygotsky, 2001) and to the history of the action and of some, not necessarily specified, aspects of society.

Throughout this dynamic relationship, subjects took turns at internalizing not only the images produced and posted by others, but also how individuals and audiences relate materially or mentally to their content. Association with others through communication (Glăveanu, Gillespie \& Valsiner, 2014) mediated both by Facebook and by each post was essential during the inception of the research. The developmental interdependence between mind and culture was exemplified (Valsiner, 2007) through potentially creative actions evidenced in mostly affective, but also relaxed and inspirational posts, by way of the interviews given by each author. As well as the interviews with P9 and P11, who referred positively even to grief, with expressions like "remembering with joy" and "our days were full of affection," the collected posts may have once revealed their authors' positive emotional states. However, during that period, they also connote nostalgia and feelings of loss, absence, or bereavement, which can be both retrospective and prospective (Boym, 
2007), respectively when feelings transport one to the past, then back to the present with a chance to shape the future.

This leads me to assume that instead of creating new posts mostly drawn from the present people can post images of past experiences to temporarily conceal a today when they are locked down and barred from socializing outside the home. Thus, re-posting can provide an answer in an uncomfortable present and possibly prepare the authors and even members of their audiences for a more than usually uncertain future. In other words, it may adaptively contribute to mental flexibility, to a changed view of new departures, beyond the cognitive scope, if required (Lubart, Zenasni, \& Barbot, 2013). In this sense, re-posting may typify a response to fear and uncertainty, and a strong awareness of losing control, as well as stress, anxiety and depression, which were not mentioned by the participants but do illustrate a concern related to re-posting. In this case, then, creativity is more about shared meaning-making than simply the individual action of re-posting itself. As hard as technology may try to predict the way people will communicate with each other, it is not successful every time and should change strategies from time to time, in order to follow the way people themselves change in line with technological affordances.

We may also surmise that some feelings or emotions need materiality in the shape of images to mediate the communication, in line with the instantaneity of the social network, which is the intrinsic value of Facebook. The images expose a collective trauma unavoidably shared, possibly questioning or equally reinforcing a pattern of personal posts full of happiness and 'positivity' in the environment, despite many other feelings about the current period which, in other sorts of posts made by many of the same authors would reinforce the search for self-realization denoted by all participants and shared, for example, with bitterness regarding Brazilian politics and health issues.

As most common human experience is constrained during the lockdown caused by the pandemic, acts of creation and communication like the aforementioned ones need to be redrawn. In many 'real' cases, it is pointless and sometimes even impossible to recall past events as contextualized by photographs ready for re-posting. Actually, when the lockdown ends, this frequent practice of re-posting on Facebook should reduce, but each poster may discover unique ways to think and feel, both to recollect and to overcome the distresses of the pandemic. These connected practices of feeling and thinking might, more than usually, consider the perspective of others. They also should be expressed briskly, because people need to respond to uncertainty by moving in some direction towards the future. For when physical contact becomes a risk and bodily movement is lim- 
ited, thinking, imagining or creating can produce adaptive or even absurd reactions, contributing to psychological imbalance.

At times when the only means of movement for many people, is remote, not only do meanings change but the materiality of places, people and events changes as well because people use immobile devices to compensate the lack of physical and unfettered movement. This allows me the assumption according to which people can create a new territory through their participation in social media in search not only to their sovereignty (Reviglio \& Agosti, 2020), but towards other different intentions. The notional journey from one place, person or event to another (Sheller \& Urry, 2004) was already habitual and potentially favorable to creativity, as long as people could use media devices to: access updated information and communicate with others in a different mode observing that people throughout the world were in the same boat, or obtaining the support of others who have similar experiences of anxiety and trauma (Douglas et al., 2009).

The teaching profession, for example, represented by half of the participants, might learn more about the potential of technology, confront their disquiet, and take more risks. They might join together to provide support for their students, analyze their needs and accompany them. Otherwise, what will be the effects on their jobs and on education in general? The same applies to many other professionals from whom inventive activities are sought. Resourceful action like posting can be affected by the transience of the current pandemic, which leads people to legacy post, yet but by so doing they are also still oriented toward the future, as creative actions usually are (Glăveanu, 2015), no matter how uncertain that future may be. The messages' original meanings were posted by their authors and audiences, but now, internally re-shaped by each author and their audiences, as well as Facebook, the messages reflect a very different encounter with the external world, particularly on the timelines of their own author, where kindred minds must be found and positive moods or emotional states still seem to prevail.

Although the interviewees did not provide in-depth reports of narrative content, it is important to note a concern inherent in the act of re-posting. One hopes that this connection opportunity can inspire users towards present and future action and that they may feel a certain comfort in the belonging offered by social bonds, both clearly mentioned by P11 and at least referred to by P2, P3, P5, P9, and P12, in avoiding mental or emotional strain. As the legacy images depict positive interpersonal themes capable of enhancing feelings of self-worth (Pillemer et al., 2013), they can also boost self-confidence and develop cognitive resources for creativity, such as openness and risk-taking (Lubart, Zenasni, \& Barbot, 2013). 
Finally, the interviews indicate how bonds were altered by social isolation and the value of creativity in the regulation of people's emotions. Moreover, re-posting presents a means of coping with privation, not only of those close, but also of strangers, jobs, freedom, and satisfying outcomes of conviviality. This led most participants to contradict a tendency - identified in the US - of decreasing the use of social media as age increases (Hruska \& Maresova, 2020) and to spending more time on Facebook, in this case, recalling their own and other's posts.

\section{Limitations and Future Research Directions}

This study strives for a better understanding of the influence of the COVID-19 pandemic on certain kinds of creative acts. Nevertheless, it called upon only a small sample of subjects and posts drawn from the researcher's own social network, subjects able to participate thanks to their internet access, higher education level, plus time and other resources for home working. It is also vital to note the average age of the participants, almost fifty years, which can suggest particular behaviors, perhaps tinged with nostalgia, on social networks. One would expect the volume of accumulated memory to be higher than that from a younger sample, although the youngest participant did emphasize strength of Facebook as memory storage. Six collaborators also happened to be teachers, although participants were not chosen for their profession.

As the content of the posts was pertinent solely for the interviews at this stage of the research, future inquiry might investigate other, more varied content posted over a longer period. That investigation should include an extended number of younger participants. Future material could be subject to audience reaction, accompanied by the authors, in order to better understand this communicative process as it fosters creativity. This could be done by observing how the images themselves, or the new captions or comments adjoining them, generate new meanings. Other Facebook users might gather the posts, which could be gently steered towards the research questions, and afterwards shared with the researcher for analysis. The selected users would also be interviewed by members of a research team on their activities on the social network. Another prospect is a longitudinal inquiry into the social and cultural effects of posting arising from the growing number of posts sharing personal tastes in music, movies, literature and so on. All touch on legacy experience by revealing relevant elements of someone's biography while hinting at future social networking, discovering more about their contact and feeling free to like, dislike, or comment on tastes shared. 


\section{CONCLUSION}

At a time of lockdown, the New was not replaced by the Old. Yet a sense of nostalgia turned one into the other, while inspiring a look into the future. What is more, some of the experience was renewed through the very relationship of each author with the content, which one would expect to alter over time, or by comments of the author or their friends, but these went unanalyzed at this stage of the research.

In any event, with statements such as "we no longer see many young people here" (P3) and the common act of legacy posting, it seems that the Facebook users, represented by the researched sample, are struggling to find other creative ways of dealing with the pandemic, notably its long-term impact on mental wellbeing. Equally, they face the ageing of the social network, which is a constant reminder of their past, while earning more approval for such recollections during lockdown. This leads me to assume that people need, more than ever, to make the most of their actionable uncertainty (Beghetto, in press) and to find creative answers to diverse dilemmas. Alternatively, there is a growing risk that legacy posting, instead of moving people's minds and feelings forward, is no more than a naïve way to hide individual and societal melancholy. Within the literature and the empirical data, creativity is essential to resolve questions like "What's the future of human mobility?" (Glăveanu, 2020); or even, "What is the future of Facebook?" Moreover, it can strengthen the hopes for a better future.

\section{REFERENCES}

Beghetto, R. A. (in press). Uncertainty: A gateway to the possible. In V. P. Glăveanu (Ed.) The Palgrave Encyclopedia of the possible. Palgrave.

Bennett. W. L., \& Segerberg, A. (2012). The logic of connective action - digital media and the personalization of contentious politics. Information, Communication \& Society, 15(5), 739-768

Bakhtin, M. (1992). Estética da criação verbal. Matins Fontes.

Bakhtin, M. M. (2006). Marxismo e filosofia da linguagem (12 ${ }^{\underline{a}}$ ed.). Hucitec.

Barthes, R. (1984) A câmara clara. Nova Fronteira.

Bruner, J. (1997). Atos de significação. Artes Médicas.

Borges, F. T.; Linhares, R. N. (2008). Imagem e narrativa: a construção dialógica da fotografia na pesquisa qualitativa em ciências humanas. Revista Educação em Questão, 33 (19), 128-149.

Boym, S. (2007). Nostalgia and its discontents. The Hedgehog Review, Summer 2007, 7-18.

Caixeta, J., \& Borges, F. (2017). Da entrevista narrativa à entrevista narrativa mediada: definições, caracterizações e usos nas pesquisas em desenvolvimento humano. Journal of Social, Technological and Environmental Science, 6(4), 67-88. 
Celik, P., \& Lubart, T. (2016). When east meets west. In: V. P. Glăveanu (Ed.). The Palgrave handbook of creativity and culture research (pp. 37-55). Palgrave Macmillan.

Douglas P.K.; Douglas D.B.; Harrigan, D.C.; \& Douglas, K.M. (2009). Preparing for pandemic influenza and its aftermath: Emerging Mental Health Issues from the Novel Coronavirus (COVID-19) Pandemic. International Journal of Emergency Mental Health, 11(3), 1-9.

Fischer, R., Karl, J., Bortolini, T., Robinson, K., Andr. Luiz Alves Rabelo, A. L. A., Tr.m, N. T. B., \& Mattos, P. (2020). Rapid review and meta-meta-analysis of self-guided interventions to address anxiety,depression and stress during COVID-19 social distancing. [Preprint]. Retrieved from https://osf.io/fpx4s/

Formiga Sobrinho, A. B. (2019). Creative culture analysis: A way to understand how an environment is (or Isn't) favorable to creative ideas (pp. 373-389). In: I. Lebuda, \& V. P. Glăveanu (Eds.). The Palgrave handbook of social creativity research. Springer International Publishing.

Formiga Sobrinho, A. B., \& Glăveanu, V. P. (2017). Creativity, communicability and organizational culture: an introduction to the study of hierarchy as both a facilitator and constraint in organizational change. Creativity: Theories - Research - Applications, 4, 178-197.

Gheller, J. (2015). Introducing On This Day: A New Way to Look Back at Photos and Memories on Facebook. Available from: https://about.fb.com/news/2015/03/ introducing-on-this-day-a-new-way-to-look-back-at-photos-and-memories-onfacebook/ [last accessed September 28 2020]

Glăveanu, V. P. (2015). Creativity as a sociocultural act. The Journal of Creative Behavior, 49(3), 165-180. doi:10.1002/jocb.94

Glăveanu, V. P. et al. (2020). Advancing creativity theory and research: A socio-cultural manifesto. The Journal of Creative Behavior, 54, 741-745.

Glăveanu, V. P. (2020). New mobilities and psychology: Why are we still not on the move? Europe's Journal of Psychology, 16(2), 186-192, https://doi.org/10.5964/ ejop.v16i2.3117.

Glăveanu, V.P., Gillespie, A., \& Valsiner, J. (Eds.) (2014). Rethinking creativity: Contributions from social and cultural psychology. Routledge. Google. (2020). COVID-19 community mobility reports. https://www.google.com/covid19/mobility/

Girginova, K. (2017). Let the games begin: social media and creative citizenship during London's Olympic \#savethesurprise campaign. Digital Creativity, https:// doi.org/10.1080/14626268.2017.1288143 
Hargreaves, I., \& Hartley, J. (Eds.) (2016). The Creative Citizen Unbound: How Social Media and DIY Culture Contribute to Democracy, Communities and the Creative Economy. Policy Press.

Hennesey, B. (2016). The creativity-motivation-culture. In: V. P. Glăveanu (Ed.). The Palgrave handbook of creativity and culture research (pp. 125-158). Palgrave Macmillan. Hennesey, B., \& Amabile, T. (2010). Creativity. Annual Review of Psychology, 61, 569-598. Jiménez Alonso, B. \& Brescó, I. (under review). Narratives of loss: Exploring grief through photography. Qualitative Studies.

Kowal, M., Coll-Martín, T., Ikizer, G., Rasmussen, J., Eichel, K., Studzinska, A., Koszałkowska, K., Karwowski, M., Najmussaqib, A., Pankowski, D., Lieberoth, A., \& Ahmed, O. (2020). Who Is the Most Stressed During COVID-19 Isolation? Data From 26 Countries. Applied Psychology: Health and Well-being, https://iaapjournals.onlinelibrary.wiley.com/doi/10.1111/aphw.12234

Lewin-Jones. J. (2015). Humour with a purpose: creativity with language in Facebook status updates. Linguistik online, 72, 3(15). http://dx.doi.org/10.13092/lo.72.1973

Lima, C. K. T.; Carvalho, P. M. de M.; Lima, I. de A. A. S.; Nunes, J. V. A. de O; Saraiva, J. S.; Souza, R. I. de; Silva, G. L. da. (2020). The emotional impact of Coronavirus 2019-nCoV (new Coronavirus disease). Psychiatry Research, 287, 112915, https:// doi.org/10.1016/j.psychres.2020.112915

Lotman, I. (1978). A estrutura do texto artístico. Editorial Estampa.

Lubart, T. (2007). Psicologia da criatividade. Artmed.

Lubart, T. (2010). Cross-cultural perspectives on creativity. In: J. C. Kaufman, \& R. J. Sternberg (Ed.). The Cambridge handbook of creativity (pp. 265-278). Cambridge University Press.

Lubart, T., Zenasni, F., \& Barbot, B. (2013). Creative potential and its measurement. International Journal for Talent Development and Creativity, 1, 41-50.

Mainsah, H. N. (2017). Social media, design and creative citizenship: an introduction. Digital Creativity, 28, 1-17.

Marková, I., Linell, P., Grossen, M., \& Orvig, A. (2007). Dialogue in focus group. Equinos. Martino, L. C. (2001). De qual comunicação estamos falando? In A. Hohlfeldt, L. C Martino, \& V. V. França (Eds.), Teorias da Comunicação: Conceitos, escolas e tendências (pp. 11-25). Vozes.

Pérez-Fuentes, M. del C., Jurado, M. del M., Linares, J. J. G., Ruiz, N. F. O., Márquez, M. del M. S., \& Saracostti, M. (2019). Self-expressive creativity in the adolescent 
digital domain: personality, self-esteem, and emotions. International Journal of Environmental Research and Public Health, 16, 4527. https://doi.org/10.3390/ ijerph16224527

Pillemer, D. B., Thomsen, D., Kuwabara, K. J., \& Ivcevic, Z; (2013). Feeling good and bad about the past and future self. Memory, 21(2), 210-218.

Reviglio, U., \& Agosti, C. (2020). Thinking outside the black-box: The case for "algorithmic sovereignty" in social media. Social Media + Society, April-June, 1-12.

Savas, Ö. (2017). Facebook communities about nostalgic photos of Turkey: creative practices of remembering and representing the past. Digital Creativity, 28, 48-57.

Sheller, M., \& Urry, J. (2004). The new mobilities paradigm. Environment and Planning, 38, 207-226. https://doi.org/10.1068/a37268

Silva, C. C. da; Borges, F. (2017). Análise Temática Dialógica como método de análise de dados verbais em pesquisas qualitativas. Linhas Críticas, 23, 245-267.

Sritharan, J; Sritharan, A. (2020), Emerging mental health issues from the novel coronavirus (COVID-19) pandemic. Journal of Health and Medical Sciences, 3, 157-162.

Navarro, J. G. (2020). Brazil: Facebook user share 2020, by age group. Available from: https://www.statista.com/statistics/866282/facebook-user-share-brazil-age/ [last accessed November 03 2020].

Stokes, P. D. (2007). Using constraints to generate and sustain novelty. Psychology of Aesthetics, Creativity, and the Arts, 1, 107-113.

Tansey, C. M.; Louie, M; Loeb, M. et al. (2007). One-year outcomes and health care utilization in survivors of severe acute respiratory syndrome. Archives in Internal Medicine, 167, 1312-1320.

Tateo, L. Fear. (2016) In: V. P. G Glăveanu, L. Tanggaard., \& C. Wegener. (Eds.). Creativity - a new vocabulary (pp. 43-51). Palgrave Macmillan.

Valsiner, J. (2014). An invitation to cultural psychology. Sage.

Valsiner, J. (2007). Culture in minds and societies: Foundations of cultural psychology. Sage.

Vygotski, L. S. (2001). A construção do pensamento e da linguagem. Martins Fontes.

World Health Organization. (2020). Coronavirus. https://www.who.int/health-topics/ coronavirus\#tab=tab_1

Zittoun, T., \& Gillespie, A. (2015). Integrating experiences: Body and mind moving between contexts. The Annual Niels Bohr Professorship lecture in Cultural Psychology. Available from: http://www.ccp.aau.dk/digitalAssets/77/77085_zittoun-gillespie_bodyand-mind-moving-between-contexts.pdf [last accessed June 24 2020]. 
Zittoun, T., Valsiner, J., Gonçalves, M. M., Salgado, J., Vedeler, D., \& Ferring, D. (2013).

Human development in the life course: Melodies of living. Cambridge University Press.

Corresponding author at: Asdrúbal Borges Formiga Sobrinho, E-mail: asdru_bal@uol.com.br 